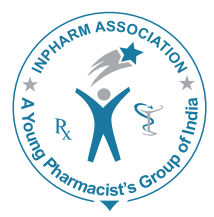

\title{
Validation of liquid chromatography-tandem mass spectrometry for mevalonate in human plasma: Incompetent effects between treated atorvastatin $\&$ its combination with olmesartan in cardiovascular patients
}

\author{
Rakesh Das, Tapan Kumar Pal* \\ Department of Pharmaceutical Technology, Bioequivalence Study Center, Jadavpur University, Jadavpur, \\ Kolkata, West Bengal, India
}

\begin{abstract}
Aim: To develop a simple and sensitive liquid chromatography-tandem mass spectrometry (LC-MS/MS) method validation for the quantification of mevalonate (MVA), an endogenous compound responsible for synthesis of cholesterol in human plasma. Settings and Design: The method was validated and impended for application on human to study the concentration of MVA in plasma level after administration of atorvastatin (ATVS) individually and with combination to olmesartan (OLM). Materials and Methods: The assay procedure involved the isolation of MVA from plasma samples using solid-phase extraction, preconditioned cartridge, washed with methanol followed by $0.1 \mathrm{~N} \mathrm{HCl}$. The analytes were eluted with $3 \times$ $0.5 \mathrm{ml}$ of methanol and evaporated to dryness Nitrogen stream. The residue was reconstitute for LCMS/MS analysis, were chromatographic separation was carried on a HyPurity advance, $50 \times 4.6 \mathrm{~mm}$ column with a mobile phase $10 \mathrm{mM}$ ammonium formate $(\mathrm{pH}=8)$ and Acetonitrile. The flow rate was $0.8 \mathrm{ml} / \mathrm{min}$ throughout the process. The LC, Agilent 1290 coupled to electrospray ion mass spectrometer. Results: The developed method was validated for specificity, accuracy, precision, stability, linearity, sensitivity, and recovery. The method was linear and found to be acceptable over the range of $50-1000 \mathrm{ng} / \mathrm{ml}$. The method was successfully applied for the drug interaction study of ATVS + OLM by quantifying changes in levels of MVA in hypertensive patients. Conclusion: The study revealed concentration levels of MVA in ATVS + OLM compared to ATVS as single treated condition are nearly equal. This conclude that, MVA synthesize equal level of blood cholesterol on both the stage, but failed to reduce BP synergistically, that associate with vascular plague formation.
\end{abstract}

Key words: Atorvastatin, human plasma level, liquid chromatography-tandem mass spectrometry, mevalonate, olmesartan

\begin{tabular}{|c|l|}
\hline \multicolumn{2}{|c|}{ Access this article online } \\
\hline \multicolumn{3}{|c|}{ Journal Sponsor } & $\begin{array}{l}\text { Website: } \\
\text { www.jyoungpharm.org }\end{array}$ \\
\hline \multirow{2}{*}{ www.phcog net } & $\begin{array}{l}\text { DOI: } \\
\text { 10.5530/jyp.2014.2.8 }\end{array}$ \\
\hline
\end{tabular}

\section{INTRODUCTION}

A method for estimating the cholesterol content of the serum low-density lipoprotein fraction involves measurement of fasting plasma total cholesterol, triglyceride, and high-density lipoprotein cholesterol concentrations without use of preparative ultracentrifuge. ${ }^{1}$ Cholesterol can be analyzed routinely

*Address for correspondence:

Prof. Tapan Kumar Pal, Professor, Department of Pharmaceutical Technology, Jadavpur University, Jadavpur, Kolkata-32,

West Bengal, India.E-mail: tkpal12@gmail.com 
by gas chromatography (GC)-flame ionization detector without derivatization; however, other methods, especially high-performance liquid chromatography (HPLC) coupled with different detectors, can also be used. For research purposes, HPLC-ultraviolet/visible/ photodiode array detector with nondestructiveness is preferred. More advanced methods, such as GC/HPLCisotope dilution/mass spectrometry (MS), are primarily used for quality control purposes. ${ }^{2}$ A simple and robust liquid chromatography (LC)-MS based methodology for the investigation of lipid mixtures is described and its application to the analysis of human lipoprotein associated lipids is demonstrated. ${ }^{3}$ A new sensitive and specific nonradioisotope assay method to measure the activity of 3-hydroxy-3-methyl-glutaryl-coenzyme A (HMG-CoA) reductase, the rate-controlling enzyme in the cholesterol biosynthetic pathway. This method was based upon a stable isotope dilution technique by LC tandem MS using electrospray ionization in positive mode. ${ }^{4}$ Proposal of a rapid and versatile reverse phase-HPLC method for assaying HMG-CoA reductase activity capable of monitoring the levels of both substrates (HMG-CoA and nicotinamide adenine dinucleotide phosphate) and products (CoA, mevalonate [MVA], and nicotinamide adenine dinucleotide phosphate + ) in a single 20 min run with no pretreatment required. ${ }^{5}$ A simple, rapid, specific, and sensitive thin-layer chromatography method has been developed for the quantitative estimation of mevalonic acid in leaves of medicinal plants; Artemisia annua, Psorelia corylifolia, Vinca rosea, Withania somnifera and Barleria proinites. The assay procedure involved conversion of MVA to its lactone, mevalonolactone (MVAL). Mevalonic acid was extracted from the leaf tissues of plants. ${ }^{6}$ The rate of cholesterol synthesis in tissues determines the concentration of mevalonic acid/MVA in plasma. $^{7}$ Urinary excretion of mevalonic acid was investigated as an indicator of cholesterol synthesis. The analysis of urinary MVA, either in $24 \mathrm{~h}$ collection or in a single morning sample, is an attractive method for evaluation of long and very short-term changes of the rates of cholesterol synthesis. ${ }^{8}$ The main challenge in developing and validating a method for determining MVA in human plasma was that MVA is a polar, endogenous moiety that circulates in the blood stream at nanogram levels. In most methods, the extraction of MVA from plasma was carried out using ion exchange resins in the form of MVAL. ${ }^{9,10}$ A simple, specific, and sufficiently sensitive LC-tandem MS (negative-ion electrospray ionization) methodology to determine mevalonic acid in human plasma is described, and its application to the analysis of rat plasma MVA levels after rosuvastatin administration is demonstrated. ${ }^{11}$

\section{EXPERIMENTAL}

\section{Chemicals and reagents}

The standard powder of 42147 - $5 \mathrm{mg}$ (R-S)-MVA lithium salt (lot. No. BCBJ74375) was obtained from Sigma-Aldrich (FLUKAR analytical, product of Switzerland), and the internal standard (IS), deuterated MVAL, was from CDN Isotopes. All solvents and other reagents were of Merck analytical grade. Control human plasma (heparin anticoagulant) for the preparation of quality control samples was obtained from a blood bank and stored at $70^{\circ} \mathrm{C}$ before use.

\section{Instrumentation, chromatographic conditions and MS/MS condition}

\section{Instrumentation}

The LC, Agilent 1290-column, Model G1316C (Agilent Technologies), Wellplate Sampler 1290-ALS, Model G4226A; Binary pump 1290-Bin Pump, Model G4220A; coupled to electrospray ion (ESI) mass spectrometer (MS QQQ).

\section{Chromatographic condition}

Chromatographic separation was carried on a Hypurity Advance, $50 \mathrm{~mm} \times 4.6 \mathrm{~mm}$ column. The column was maintained at temperature $45^{\circ} \mathrm{C}$. The mobile phase consisted of ammonium formate buffer $(10 \mathrm{~mm}$, $\mathrm{pH} 8.0$, adjusted with liquid ammonia) and acetonitrile $(30: 70, \mathrm{v} / \mathrm{v})$. The flow rate was $0.8 \mathrm{ml} / \mathrm{min}$, and the total run time was $2 \mathrm{~min}$. Maximum pressure of binary pump is 800 (bar) and maximum flow gradient is $100 \mathrm{ml} / \mathrm{min}$. Compress solvent A (10-6 bar) is 50 and compress solvent B (10-6 bar) is 115 .

\section{MS/MS condition}

The liquid chromatograph (Agilent 1290; Agilent Technologies, Inc., Palo Alto, CA, USA) was coupled to a MS QQQ with a ESI source and was used in negative ionization polarity with the following source settings. The ion transfer tube temperature is $350^{\circ} \mathrm{C}$. The nebulizer gas is Nitrogen and pressure is 50 p.s.i. The collision-activated dissociation Helium gas pressure was 5 p.s.i., the capillary voltage was $3000 \mathrm{~V}$ and $+4000 \mathrm{~V}$. Fragmentation potential was $80 \mathrm{~V}$; entrance potential was $10 \mathrm{~V}$; collision energy was $10 \mathrm{~V}$. The multiple reaction monitoring pair monitored was $\mathrm{m} / \mathrm{z} 147 \rightarrow 59$ for MVA and $\mathrm{m} / \mathrm{z} 154 \rightarrow 59$ for D7-MVA, with a dwell time of $100 \mathrm{~ms}$. The autosampler cooler was maintained at $10^{\circ} \mathrm{C}$. Analyst software (MassHunter) was used for data registration and calibration. 
Preparation of calibration standards and quality control samples

The calibration standards were prepared by spiking human plasma with standard MVA with corresponding IS (MVA-D7) to obtain resultant concentrations of 50, 100, 200, 400, 600, 800, and $1000 \mathrm{ng} / \mathrm{mL}$. The developed method was validated using three different quality control samples by spiking MVA in human plasma at 50, 400, and $1000 \mathrm{ng} / \mathrm{mL}$ to represent low quality controls (LQC), middle quality controls (MQC), and high quality controls (HQC), respectively.

\section{Sample extraction procedure}

Samples were thawed in water. Plasma aliquots of $500 \mu \mathrm{l}$ were added to a glass tubes contain IS $(100 \mu \mathrm{l}, 200 \mathrm{ng} / \mathrm{ml})$, $0.1 \mathrm{~N} \mathrm{HCl}(1 \mathrm{ml})$, and water $(0.5 \mathrm{ml})$; the tubes were than vortex-mixed. The sample solution was keep aside for 30 min to convert MVA to MVAL. Each sample solution was individually transferred to a solid-phase extraction cartridge that had been preconditioned with methanol $(1 \mathrm{ml})$ followed by $0.1 \mathrm{~N} \mathrm{HCl}(1 \mathrm{ml})$. Each cartridges was washed with $0.1 \mathrm{~N} \mathrm{HCl}(1 \mathrm{ml})$ followed by water $(1 \mathrm{ml})$ and $15 \%$ methanol in water. The cartridges were allowed to dry. The analytes were eluted with $3 \mathrm{ml} \times 0.5 \mathrm{ml}$ of methanol. The resulting methanol extract solutions were evaporated to dryness under a stream of nitrogen at 15 p.s.i. and $40^{\circ} \mathrm{C}$ bath temperature for $15 \mathrm{~min}$. The residues were reconstituted in $0.2 \%$ ammonium hydroxide solution $(100 \mu \mathrm{l})$ to convert MVAL to MVA. Aliquots of $10 \mu \mathrm{l}$ were injected into the LC-MS/MS apparatus for analysis.

\section{Method validation}

\section{Selectivity and specificity}

MVA is an endogenous compound present in humans, as a part of specificity studies plasma devoid of MVA was obtained from patients suffering from Addison's disease, which are having no circulating MVA in them. The obtained plasma sample was processed by the solid-phase extraction procedure. The samples were chromatographed to determine to which extent endogenous plasma components may contribute to the peak interference at retention times of MVA. Furthermore, the eqi-volume of spiked plasma of standard MVA and MVA D-7 (IS) represent the exact location of peaks and ratio of extracted MVA from plasma with this methodology.

\section{Linearity}

Calibration curves were prepared by adding a known amount of MVA as well as MVA-D7, IS (50, 100, 200, 400,
600,800 , and $1000 \mathrm{ng} / \mathrm{mL}$ ) to $0.5 \mathrm{~mL}$ of blank plasma. The samples were extracted as described previously. The standard curves were constructed by plotting the peak area ratio of MVA standard concentration and of MVA D-7 (IS) upon X- and Y-axis concentration ranges. Linearity was assessed by observing the values of the coefficient of correlation $\left(R^{2}\right)$ of linearity plots, nearness of values near to one suggested linearity of responses. Furthermore, the linearity of each standard curve was confirmed by plotting the peak area of MVA. The unknown sample concentrations were calculated from the weighted $\left(1 / \mathrm{x}^{2}\right)$ linear regression analysis of the standard curve.

\section{Precision and accuracy}

Inter- and intra-day precision studies were done by injecting quality control dilutions (50, 400, and $1000 \mathrm{ng} / \mathrm{mL}$ ) as described earlier $(n=12)$ in developed chromatographic method. Peak areas were calculated for $\%$ relative standard deviation (RSD) values.

\section{Extraction recovery}

To calculate recovery of the extraction procedure, 12 replicates of quality control samples of MVA (50, 400, and $1000 \mathrm{ng} / \mathrm{mL}$ ) were extracted and analyzed. The peak area was compared with the same concentrations of unextracted standards of MVA reconstituted in methanol.

\section{Stability}

In bench top stability, 12 replicates of low and high quality controls of MVA (50 and $1000 \mathrm{ng} / \mathrm{mL}$ ) were analyzed at 0 and $6 \mathrm{~h}$ at room temperature and the deviation was calculated. In freeze-thaw stability, 12 replicates of low and high quality control samples of MVA were prepared, frozen at $-20^{\circ} \mathrm{C}$ and analyzed after two and three freeze-thaw cycles. Long-term stability was examined for 14 days by taking 12 replicates of high and low quality control samples. The mean concentration was taken into consideration, which was compared with 0 day sample concentration.

\section{Limit of detection (LOD) and limit of quantitation (LOQ)}

The LOD and LOQ were determined by injecting progressively low concentrations of the standard solution under the chromatographic conditions. LOD and LOQ were calculated directly from the calibration plot. LOD and LOQ were calculated as $3.3 \sigma / \mathrm{S}$ and $10 \sigma / \mathrm{S}$, respectively, where $\sigma$ is the standard deviation of intercept and $S$ is the slope of the calibration plot. The LOD was defined as a signal-to-noise $(\mathrm{S} / \mathrm{N})$ ratio of 3:1 and the LOQ was defined as an $\mathrm{S} / \mathrm{N}$ ratio of 10 .

Journal of Young Pharmacists Vol 6 • Issue 2 • Apr-Jun 2014 


\section{Study design}

The study on human volunteers was carried under approval of Ethics Committee "HURIP Independent Bioethics," Ibrahimpur Road, Kolkata, India. The study was performed along with patients consent and under the supervision of the doctor. Twelve hypertensive patients aged between 21 and 30 years, noninfected, not under any antibiotics, steroid and other medicines therapy for a month, except specific cardiovascular drug provided by experts for this study. The patients were routinely supervised and also prescribed with a single category of medicines i.e. olmesartan (OLM) and atorvastatin (ATVS), according to their therapeutic regimens.

The collection of blood plasma was basically done 3 times per individual for 7-14 days in the first stage without any drug administration. Secondly, along with a combination of OLM + ATVS and thirdly with only single hypertensive drug i.e. OLM. First stage was for 1 week in which the patients were devoid of any antihypertensive drugs. The patients were evaluated for demography and measurement of BP followed by withdrawal of blood to quantify the levels of MVA.

\section{RESULTS AND DISCUSSION}

\section{Method validation}

\section{Selectivity and specificity (matrix effect)}

Blank plasma obtained from patients suffering from Addison's disease was used for studies. The plasma was used to mark any endogenous interference. A representative chromatogram of the plasma blank is shown in Figure 1a. No additional peaks of endogenous substances were observed. Figure 2a shows the chromatograms of calibration standard containing MVA spiked in plasma with MVA D-7 (IS).

\section{Linearity}

Linear calibration curves (Figure 1b) with correlation coefficients near to 0.999399 were obtained over the concentration range of MVA (50, 100, 200, 400, 600, 800, and $1000 \mathrm{ng} / \mathrm{mL}$ ) to $0.5 \mathrm{~mL}$ of blank plasma. The coefficient of regression, i.e. $r^{2}=0.99947360808176$ was obtained indicating linearity of results and an excellent correlation between peak area ratio for each concentration of MVA. The plasma spiked MVA standard versus MVA D-7 (IS) calibrated curve (Figure $2 \mathrm{~b}$ and $2 \mathrm{c}$ ) represents regression line linearity equation of $\mathrm{y}=1.0205027790797 \mathrm{x}-10.015436300154$.

\section{Accuracy and precision}

Method performance was evaluated as accuracy and precision as shown in Tables 1 and 2, determined by 12 replicate analyses for MVA at three concentration levels, i.e. LQC $(50 \mathrm{ng} / \mathrm{mL}), \mathrm{MQC}(400 \mathrm{ng} / \mathrm{mL})$ and HQC $(1000 \mathrm{ng} / \mathrm{mL})$, each on the same analytical run. Inter-assay precision and accuracy were calculated after repeated analysis in three different analytical runs. Results concluded the repeatability of the method, including both sample processing and chromatographic measurement. Recovery

Table 1: Accuracy study of developed method for MVA in human plasma

\begin{tabular}{llcc}
\hline Sr. No. & $\begin{array}{l}\text { Quality control } \\
\text { samples of ALD }\end{array}$ & $\begin{array}{c}\text { Recovered } \\
\text { amount }(\mathbf{n g} / \mathbf{m L})\end{array}$ & $\begin{array}{c}\text { Accuracy } \\
(\%)\end{array}$ \\
\hline 01 & LQC & $47.5 \pm 2.1$ & 95.0 \\
02 & MQC & $382.66 \pm 3.6$ & 95.67 \\
03 & HQC & $991.32 \pm 10.9$ & 99.13 \\
\hline
\end{tabular}

Table 2: Precision study of developed method for MVA in Human Plasma (Inter and Intraday)

\begin{tabular}{llccccc}
\hline Sr. No. Quality & \multicolumn{2}{c}{ Inter-day precision } & & \multicolumn{2}{c}{ Intra-day precision } \\
\cline { 3 - 4 } \cline { 6 - 7 } $\begin{array}{l}\text { control } \\
\text { samples } \\
\text { of MVA }\end{array}$ & $\begin{array}{c}\text { Recovered } \\
\text { amount (ng/mL) }\end{array}$ & \%RSD & $\begin{array}{c}\text { Recovered } \\
\text { amount (ng/mL) }\end{array}$ & $\% R S D$ \\
\hline 1 & LQC & $46.98 \pm 0.97$ & 1.82 & $48.76 \pm 0.72$ & 1.85 \\
2 & MQC & $389.62 \pm 3.7$ & 1.77 & $392.13 \pm 4.9$ & 1.68 \\
3 & HQC & $988.92 \pm 11.05$ & 1.69 & $993.31 \pm 10.55$ & 1.72 \\
\hline
\end{tabular}

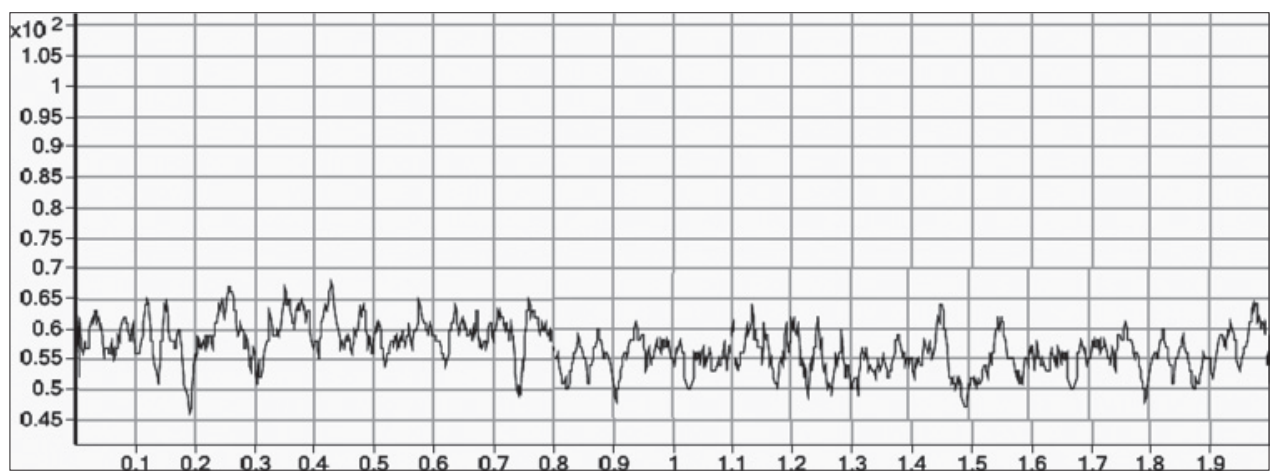

Figure 1a: Liquid chromatography-tandem mass spectrometry trace of mevalonate in human plasma (blood plasma sample) of hypotensive patient 


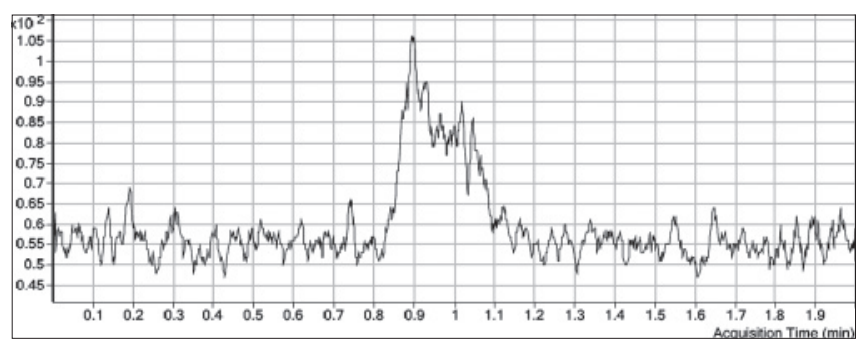

Figure 1b: Liquid chromatography-tandem mass spectrometry trace of mevalonate spiked in human plasma (quality control standard: $50 \mathrm{ng} / \mathrm{ml}$ )

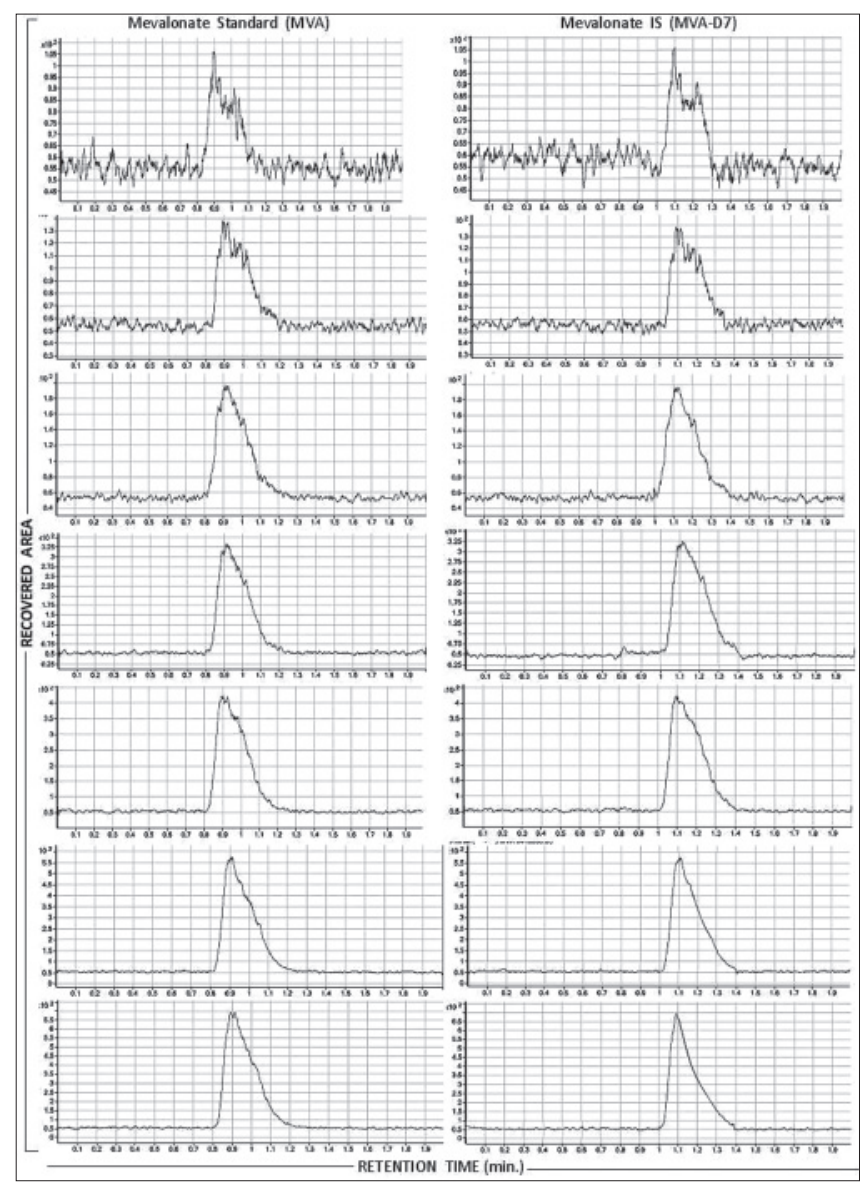

Figure 2a: Chromatograms of standard (mevalonate [MVA]) versus internal standard (MVA-D7) as area peak ratio

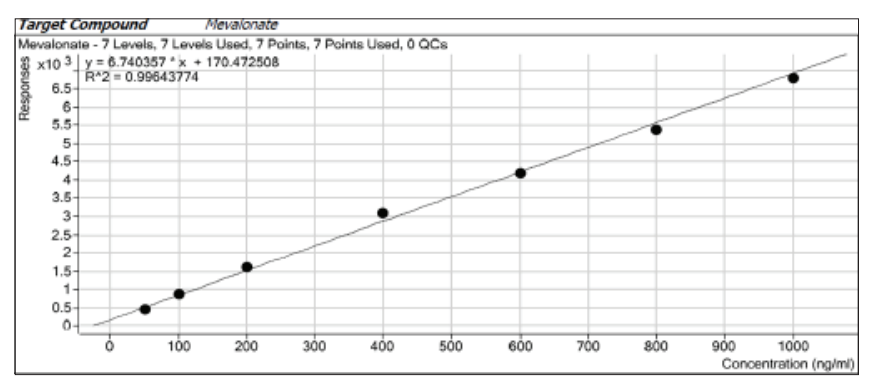

Figure $\mathbf{2 b}$ : Linearity curve plotting the peaks area of standard mevalonate in response versus retention time (minute) graph results were subjected statistically analysis and $\%$ RSD were recorded. The $\%$ RSD is a ratio of standard deviation to mean in percent. $\%$ RSD values were small indicating good accuracy of results. Inter- and intra-day results also were good as the $\%$ RSD values were low.

\section{Extraction recovery}

Extraction recovery of MVA was determined by comparing peak areas obtained from extracted plasma samples with those found by extracting blank matrices through the extraction procedure and spiking with a known amount of MVA. The results showed that the mean extraction recovery of MVA was $>85 \%$ at three different quality control such as LQC, MQC, HQC, respectively (Table 3).

Averaged for 12 measurements at each concentration level $(n=12)$;

$\%$ recovery $=($ response of extracted spike $) /($ response of post-extracted spike) $\times 100$.

\section{Stability}

In bench top stability, six replicates of LQC and HQC of MVA (50 and $1000 \mathrm{ng} / \mathrm{mL}$ ) analyzed at 0-6 h at room temperature resulted in recovery in acceptable ranges, at $0 \mathrm{~h}$ the recovery of MVA from plasma was $98.4 \%$ for LQC and $101.7 \%$ for HQC, whereas after $6 \mathrm{~h}$ the extraction recovery of MVA was $95.3 \%$ for LQC and $100.9 \%$ for HQC. The recovery of MVA for freeze-thaw stability studies was

Table 3: The percentage extraction recovery of MVA from plasma

\begin{tabular}{llc}
\hline Sr. No. & Quality control samples of MVA & Mean \% recovery \\
\hline 1. & LQC & 96.3 \\
2. & MQC & 92.7 \\
3. & HQC & 87.8 \\
\hline
\end{tabular}

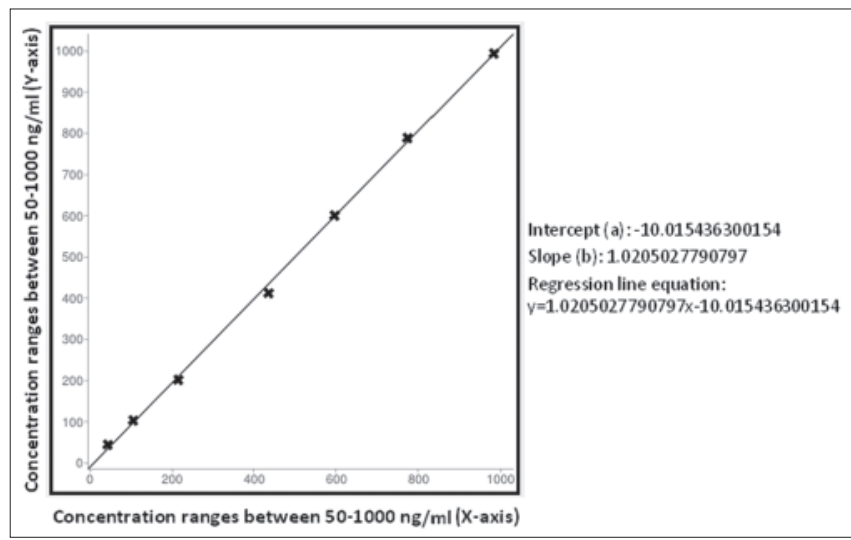

Figure 2c: Scatterplot linear regression lines and lowess for the peak area ratio of respective mevalonate (MVA) (standard) concentrations and MVA-D7 (internal standard) 
found to be within the limits as per the guidelines. For LQC sample mean recovery for second and third freezethaw stability cycle were $98.3 \%$ and $96.8 \%$, respectively, for HQC samples the mean recoveries for second and third freeze-thaw stability cycle were $103.4 \%$ and $103.2 \%$, respectively, which were well inside the acceptable ranges as per the guidelines (i.e. $\pm 15 \%$ ). Long-term stability results for extraction recovery of LQC and HQC samples resulted in acceptable recoveries concluding the method suitable to stability studies for long periods.

\section{Sensitivity studies (LOD and LOQ)}

The method was confirmed for sensitivity by estimating LOD and LOQ. The method exhibited excellent sensitivity by demonstrating LOD of $0.97 \mathrm{ng} / \mathrm{ml}$ and LOQ of $2.33 \mathrm{ng} / \mathrm{ml}$.

\section{Application of the analytical method in pharmacokinetic studies}

The developed LC/MS/MS method for quantification of MVA in plasma was applied for the drug interaction study in hypertensive patients under the antihypertensive drug therapy. Blood was collected after dosing thereafter immediately the blood pressure was observed in lying posture for same individual patient in three stages and similarly with the rest of the volunteer (patients). Table 4 shows that there were significant reductions $(P<0.001)$ in the blood pressure of volunteers with OLM when compared to without treatment stage.

The plasma concentration of MVA was calculated in the hypertensive human volunteers by using given developed method. There were significant decrease $(P<0.001)$ in the level of MVA in ATVS + OLM treated stage when compared to the without treatment stage in human volunteer. Whereas the concentration of MVA in the OLM treated stage was lower than the detection limit as shown in Table 5.

\section{CONCLUSION}

The present study was undertaken to develop a sensitive method for quantification of MVA in human plasma. The developed LC/MS/MS method was validated in accordance to guidelines and confirmed to be specific, selective, linear, accurate, precise, and sensitive. The method

Table 5: The effect of different antihypertensive treatment stage over the plasma concentration of MVA of hypertensive human volunteers

\begin{tabular}{lccc}
\hline Sr. No. & \multicolumn{3}{c}{$\begin{array}{c}\text { Plasma concentration of MVA of Twelve patients in } \\
\text { three different stages of treatment }\end{array}$} \\
\cline { 2 - 4 } & $\begin{array}{c}\text { Without drugs } \\
\text { Conc. in } \mathbf{~ g / m L}\end{array}$ & $\begin{array}{c}\text { ATVS } \\
\text { Conc. in } \mathbf{n g} / \mathbf{m L}\end{array}$ & $\begin{array}{c}\text { ATVS+OLM } \\
\text { Conc. in } \mathbf{~ g} / \mathbf{m L}\end{array}$ \\
\hline 1 & 77.2871 & 51.2518 & 51.8674 \\
2 & 76.2911 & 48.2251 & 48.2121 \\
3 & 75.6999 & 48.1121 & 46.3342 \\
4 & 75.4732 & 48.5611 & 47.2546 \\
5 & 74.8612 & 47.8235 & 42.5331 \\
6 & 69.8871 & 50.3669 & 44.6673 \\
7 & 77.002 & 53.4575 & 50.2453 \\
8 & 77.5024 & 52.4228 & 53.2111 \\
9 & 78.1134 & 53.1582 & 50.7215 \\
10 & 76.0708 & 53.9304 & 49.5423 \\
11 & 77.7603 & 50.0309 & 49.8469 \\
12 & 75.7622 & 50.3236 & 49.9254 \\
Mean \pm SEM & $75.9758 \pm 0.6797$ & $50.6386 \pm 0.6291^{\star \star *}$ & $48.6967 \pm 0.8776^{\star \star *}$ \\
\hline Foot notes: Values are mean \pm SEM $(n=12),{ }^{* * *} P<0.0001$ & when compared to \\
Without drug treated condition. ND: Not detected &
\end{tabular}

Table 4: The effect of different antihypertensive treatment over the blood pressure (systolic/diastolic) of hypertensive human volunteers

\begin{tabular}{|c|c|c|c|c|c|c|c|}
\hline \multirow[t]{3}{*}{ Sr. No. } & \multirow[t]{3}{*}{$\begin{array}{l}\text { Patients } \\
\text { gender }\end{array}$} & \multirow[t]{3}{*}{ Age } & \multirow[t]{3}{*}{$\begin{array}{l}\text { Body } \\
\text { weight }\end{array}$} & \multirow[t]{3}{*}{$\begin{array}{l}\text { Body } \\
\text { height }\end{array}$} & \multicolumn{3}{|c|}{$\begin{array}{c}\text { Blood pressure (systolic \& diastolic pressure) } \\
\text { measurement \& blood collection }(4 \mathrm{ml}) \text { in three stages }\end{array}$} \\
\hline & & & & & Without drug & ATVS+OLM & OLM \\
\hline & & & & & 124/82 (control) & $122 / 82$ (control) & $120 / 79$ (control) \\
\hline 1 & Male & 28 & 84 & $5.8 m$ & $176 / 117$ & $169 / 113$ & $160 / 110$ \\
\hline 2 & Female & 29 & 65 & $5.3 \mathrm{~m}$ & $182 / 123$ & $175 / 120$ & $164 / 112$ \\
\hline 3 & Male & 23 & 83 & $5.7 \mathrm{~m}$ & $185 / 126$ & $180 / 119$ & $168 / 102$ \\
\hline 4 & Male & 27 & 86 & $5.9 \mathrm{~m}$ & $165 / 119$ & $162 / 115$ & $156 / 104$ \\
\hline 5 & Male & 27 & 79 & $5.6 \mathrm{~m}$ & $171 / 128$ & $167 / 122$ & $161 / 111$ \\
\hline 6 & Male & 26 & 81 & $5.6 \mathrm{~m}$ & $157 / 110$ & $150 / 106$ & $143 / 100$ \\
\hline 7 & Female & 32 & 82 & $5.8 \mathrm{~m}$ & $179 / 119$ & $170 / 110$ & $145 / 89$ \\
\hline 8 & Male & 29 & 77 & $5.7 \mathrm{~m}$ & $184 / 130$ & $173 / 124$ & $152 / 112$ \\
\hline 9 & Male & 26 & 73 & $5.6 \mathrm{~m}$ & $174 / 121$ & $170 / 115$ & $147 / 92$ \\
\hline 10 & Male & 28 & 85 & $5.10 \mathrm{~m}$ & $169 / 118$ & $166 / 114$ & $156 / 100$ \\
\hline 11 & Female & 28 & 66 & $5.2 \mathrm{~m}$ & $172 / 122$ & $165 / 112$ & $142 / 88$ \\
\hline 12 & Female & 30 & 69 & $5.5 \mathrm{~m}$ & $177 / 125$ & $168 / 117$ & $137 / 113$ \\
\hline Mean+SEM & & & $78.27 \pm 2.21$ & $5.57 \pm 0.0721$ & $\begin{array}{l}174.25 \pm 2.35 \\
/ 121.5 \pm 1.57\end{array}$ & $\begin{array}{c}167.91 \pm 2.134 \\
/ 115.58 \pm 1.484\end{array}$ & $\begin{array}{l}152.58 \pm 2.82^{* *} \\
/ 102.75 \pm 2.66^{* *}\end{array}$ \\
\hline
\end{tabular}

Foot notes: Values are mean \pm SEM $(n=12),{ }^{* \star} P<0.0001$ when compared to without drug treated condition 


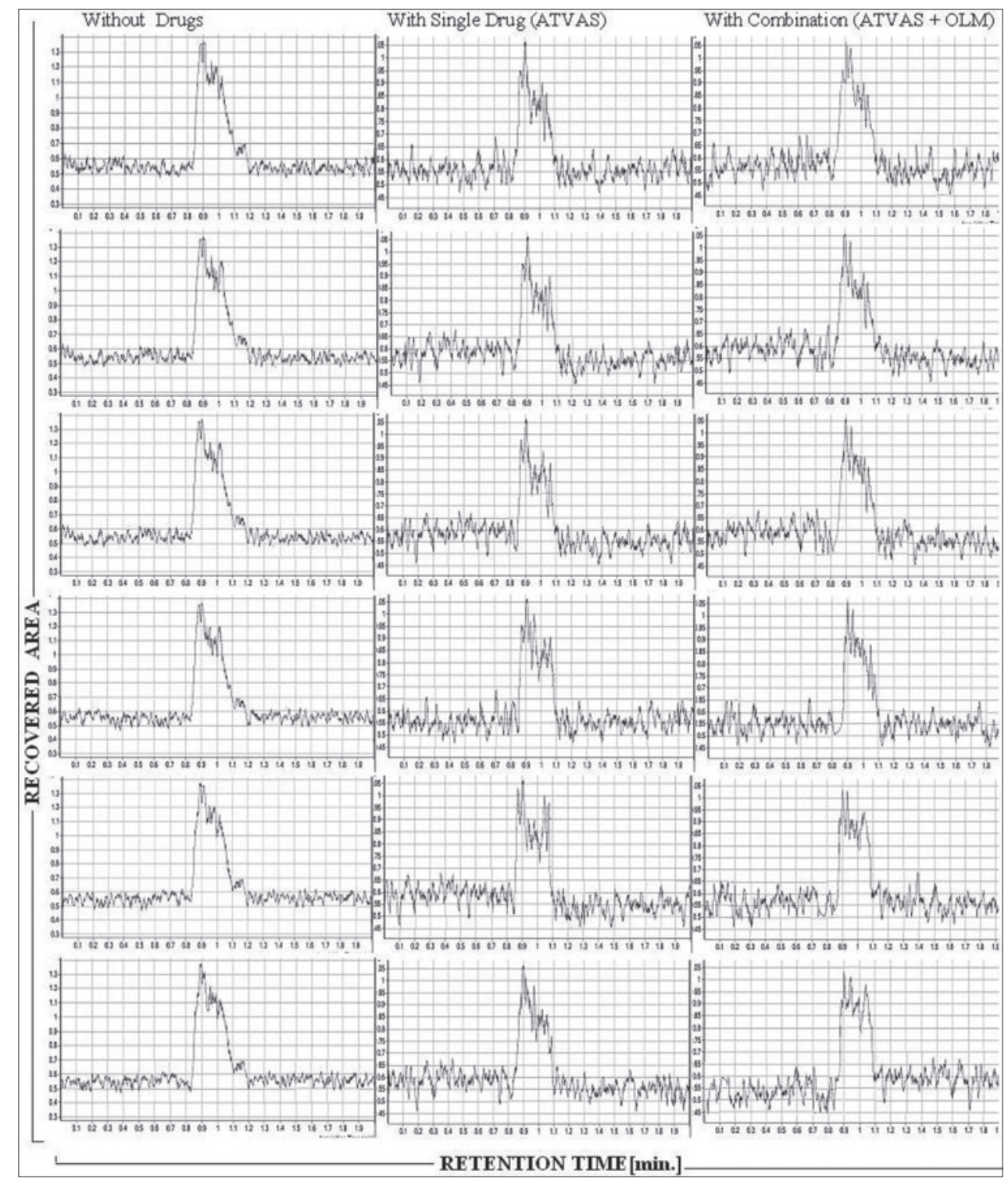

Figure 3: Chromatograms of 12 blood plasma mevalonate trace in three different stages

exhibited acceptable recovery from spiked plasma samples also the method was proved to be sensitive demonstrating excellent LOD and LOQ levels of $0.97 \mathrm{ng} / \mathrm{ml}$ and $2.33 \mathrm{ng} / \mathrm{ml}$, respectively.

The validated sensitive method was applied for pharmacokinetic studies to quantify the levels of MVA in human volunteers under therapy of ATVS, OLM, and combinations of both. The study concluded that the concentration of MVA in human volunteers treated with ATVS + OLM was similar as that of OLM treated hypertensive human volunteer, and thus the cholesterol synthesis on both cases are same nearly, although the physiological characters revealed a decrease in blood pressure of OLM treated patients as compared to ATVS + OLM treated ones. Thus, the present study concludes, failure of combination therapy for fulfilling the objective of synergistic activity, compared to individual drug treatment (Figure 3), even though the level of Cholesterol synthesized equally in both sides by its factor MVA in eqi-quantity.

\section{ACKNOWLEDGMENT}

I would like to thank my clinical investigation guide Dr. Balaram Ghosh (Associate Professor), M. Medical College, Government of West Bengal, India and supportive medical staffs for their time, advice, clinical support, and guidance. I would like to thank my colleagues Mr. Naveen Pratap Singh (Analytical Lab. Manager) in Choksi Lab (National Accreditation Board for Testing and Calibration Laboratories [NABL]), Indore, M.P., India over the entire session support in LCMS validation. 


\section{REFERENCES}

1. Friedewald W'T, Levy RI, Fredrickson DS. Estimation of the concentration of low-density lipoprotein cholesterol in plasma, without use of the preparative ultracentrifuge. Clin Chem 1972;18:499-502.

2. Dinh TT, Thompson LD, Galyean ML, Brook JC, Patterson KY, Boylan LM, et al. Cholesterol content and methods for cholesterol determination in meat and poultry. Compr Rev Food Sci Food Saf 2011;10:269-89.

3. Sommer U, Herscovitz H, Welty FK, Costello CE. LC-MS based method for the qualitative and quantitative analysis of complex lipid mixtures. J Lipid Res 2009;50:1-32.

4. Honda A, Mizokami Y, Matsuzaki Y, Ikegami T, Doy M, Miyazaki H. Highly sensitive assay of HMG-CoA reductase activity by LC-ESI-MS/MS.J Lipid Res 2007;48:1212-20.

5. Mozzicafreddo M, Cuccioloni M, Eleuteri AM, Angeletti M. Rapid reverse phase-HPLC assay of HMG-CoA reductase activity. J Lipid Res 2010;51:2460-3.

6. Ram M, Khan S, Jha P, Khan MA, Kiran U, Javed S, et al. Rapid TLC method for estimation of mevalonic acid in the leaves of medicinal plants. Chromatographia 2008;68:129-33.
7. Parker TS, McNamara DJ, Brown C, Garrigan O, Kolb R, Batwin H, et al. Mevalonic acid in human plasma: Relationship of concentration and circadian rhythm to cholesterol synthesis rates in man. Proc Natl Acad Sci U S A 1982;79:3037-41.

8. Lindenthal B, Simatupang A, Dotti MT, Federico A, Lütjohann D, von Bergmann K. Urinary excretion of mevalonic acid as an indicator of cholesterol synthesis. J Lipid Res 1996;37:2193-201.

9. Abrar M, Martin PD. Validation and application of an assay for the determination of mevalonic acid in human plasma by liquid chromatography tandem mass spectrometry. J Chromatogr B Analyt Technol Biomed Life Sci 2002;773:103-11.

10. Jemal M, Schuster A, Whigan DB. Liquid chromatography/tandem mass spectrometry methods for quantitation of mevalonic acid in human plasma and urine: Method validation, demonstration of using a surrogate analyte, and demonstration of unacceptable matrix effect in spite of use of a stable isotope analog internal standard. Rapid Commun Mass Spectrom 2003;17:1723-34.

11. Saini GS, Wani TA, Gautam A, Varshney B, Ahmed T, Rajan KS, et al. Validation of the LC-MS/MS method for the quantification of mevalonic acid in human plasma and determination of the matrix effect. J Lipid Res 2006;47:2340-5. 